\title{
Tuberculosis in Immigrants to Cartagena de Indias, Colombia
}

\author{
Dilia Fontalvo-Rivera ${ }^{*}$, Enrique Mazenett ${ }^{2}$, Luisana Cárcamo-Marrugo ${ }^{3}$, Claudia Llerena-Polo ${ }^{4}$, Doris \\ Gómez-Camargo ${ }^{1}$
}

${ }^{1}$ Program Tropical Medicine, Universidad de Cartagena, Cartagena, Colombia

${ }^{2}$ Department of epidemiology, Coosalud, Cartagena de Indias-Colombia, Colombia

${ }^{3}$ Program Tuberculosis and Leprosy DADIS, Cartagena de Indias-Colombia, Colombia

${ }^{4}$ National Institute of Health, Bogota, Colombia

Corresponding Author: Fontalvo-Rivera Dilia, MD, PhD, Program Tropical Medicine, Universidad de Cartagena, Cartagena, Colombia. Tel: +57-6525132,Email: diliafontalvor@gmail.com,dimifori@hotmail.com

Received April 9, 2020; Accepted July 30, 2020; Online Published August 9, 2020

\begin{abstract}
Introduction: Tuberculosis (TB) affects vulnerable populations. Immigrants have contributed to the increased incidence of TB. In this population, TB has some common characteristics that can lead to increased resistance to anti-TB drugs and undesired outcomes. In Cartagena de Indias, Colombia, an increase in TB cases has been observed in immigrants. Our objective is to describe the clinical and microbiological characteristics of Mycobacterium tuberculosis in the immigrant population of Cartagena de Indias, Colombia.

Methods: A descriptive study of 101 patients with a clinical and microbiological diagnosis of TB was carried out in the city of Cartagena de Indias, Colombia from December 2017 to December 2018. The clinical spectrum and sensitivity profile of M. tuberculosis to first-line anti-TB drugs were characterized by phenotypic tests and molecular markers of resistance. Confidence intervals were calculated for the estimates. Statistical significance was considered at $P \leq 0.05$.

Results: A total of 101 patients were analyzed. $8.91 \%$ (95\% Cl: 4.16-16.24\%) of the study population were immigrants. Extrapulmonary tuberculosis (EPTB) occurred more frequently among immigrants than in the native population $(44.44 \% ; 95 \% \mathrm{Cl} 13.70-78.80 \%$ vs. $4.49 \% ; 95 \% \mathrm{Cl} 1.24-11.11 \% ; P=0.002)$. The immigrants also had a higher frequency of cases with resistance $(15.22 \mathrm{vs} .44 .44 \% ; P=$ $0.051)$ and undesired outcomes, such as therapeutic failure $(8.70 \%$ vs. $33.33 \% ; P=0.001)$ and death $(4.35 \%$ vs. $44.44 \% ; P=0.001)$. Conclusion: Immigrant TB patients were more likely to present particular clinical characteristics, such as HIV coinfection, malnutrition, constitutional manifestations, extrapulmonary spread, the presence of caverns, and undesired outcomes.

Keywords: Tuberculosis, Immigrants, Resistance, Anti-Tuberculosis Drugs
\end{abstract}

Citation: Fontalvo-Rivera D, Mazenett E, Cárcamo-Marrugo L, Llerena-Polo C, Gómez-Camargo D. Tuberculosis in immigrants to Cartagena de Indias, Colombia. Int J Travel Med Glob Health. 2020;8(3):100-106. doi:10.34172/ijtmgh.2020.18.

\section{Introduction}

Tuberculosis (TB) is among the top ten causes of death in the world and is the leading cause of death by a single infectious agent. A 2019 report from the World Health Organization (WHO) stated that there were 10 million (range of 9-11.1 million) people with $\mathrm{TB}$ in the world in 2018, of which 1.2 million died (range 1.1-1.3 million). ${ }^{1}$ Two-thirds of the world's population is infected by the causative agent of TB, Mycobacterium tuberculosis. One in ten people infected with M. tuberculosis develop an active infection; the remaining ninety percent have the latent form of the disease, which can progress to reactivation $\mathrm{TB} .{ }^{2}$

TB affects vulnerable populations such as those with low economic status, persons with comorbidities such as diabetes mellitus or coinfection with HIV, and homeless individuals.
Worldwide, immigrants have contributed to the increased incidence of TB. Human migration refers to the movement of persons or groups of people from one geographical region to another across an administrative or political border with the intention of establishing themselves indefinitely or temporarily in a place other than their place of origin. ${ }^{3,4}$ A 2018 report from the International Organization for Migration (IOM) stated that the estimated number of international migrants has increased in the last 4 and a half decades. The estimated total number of international immigrants in 2015 was 243700236 people, equivalent to $3.3 \%$ of the world population. ${ }^{5,6}$

Colombia is experiencing a new surge of immigration from Venezuela. ${ }^{7}$ This study was carried out in Cartagena de Indias, a tourist city located in the Caribbean region of Colombia with an estimated population of 1089683

Copyright $(\odot 2020$ The Author(s). This is an open-access article distributed under the terms of the Creative Commons Attribution License (http:// creativecommons.org/licenses/by/4.0), which permits unrestricted use, distribution, and reproduction in any medium, provided the original work is properly cited. 
inhabitants; $5 \%$ were immigrants from Venezuela during the study period, according to the National Administrative Department of Statistics (the Spanish acronym is DANE). ${ }^{8}$ Cartagena de Indias has experienced an increase in TB cases; in 2017, the District Administrative Department of Health (DADIS) reported that there were 356 TB cases $(2.4 \%$ of which were reported in Colombia). Of these cases, 35 (9.98\%) had coinfection with HIV, and 25 (7.02\%) occurred in patients with Venezuelan nationality. Our objective is to describe the clinical and microbiological characteristics of M. tuberculosis in the immigrant population in Cartagena de Indias, Colombia.

\section{Methods}

A descriptive study of 101 patients with a clinical and microbiological diagnosis of TB was carried out in the city of Cartagena de Indias, Colombia during the period from December 2017 to December 2018. The patients came from 3 geographic areas, denominated as localities 1,2 , and 3 . The selection criteria included clinical criteria, epidemiological contact, imaging findings, Ziehl Nelsen staining, and histopathology. Participants provided a medical history, and biological samples were taken according to the type of TB (sputum, cerebrospinal fluid, pleural fluid, bone tissue) and seeded in solid culture medium. The samples were subjected to anti-TB drug susceptibility testing by automated susceptibility testing, and the markers of resistance to isoniazid and rifampicin ( $k a t G$, inh $A, r p o B$ genes) were determined by molecular biology.

Culture method for Isolation of Mycobacterium tuberculosis Biological samples were decontaminated with $4 \%$ sodium hydroxide and seeded for culturing in solid Ogawa Kudoh medium in accordance with the protocol of the Pan American Health Organization (PAHO). ${ }^{9}$ They were incubated for 8 weeks at $36^{\circ} \mathrm{C}$ and evaluated for growth every week.

\section{Phenotypic Sensitivity Test}

All samples were subjected to detection of M. tuberculosis and anti-TB drug susceptibility testing by the BD Bactec MGIT (Mycobacterial Growth Indicator Tube) 960 Mycobacteria Culture System (Becton, Dickinson and Company 7 Loveton Circle Sparks, MD 21152-0999 USA; 800-638-8663), ${ }^{10}$ in collaboration with the National Reference Laboratory of the Colombian National Institute of Health (INS). The critical concentrations of isoniazid were 0.1 and $0.4 \mu \mathrm{g} / \mathrm{mL}$, and that of rifampin was $1.0 \mu \mathrm{g} / \mathrm{mL} .^{10}$

\section{Molecular Tests}

DNA was extracted from the colonies of the cultures in solid medium using the Wizard technique (Promega $\left.{ }^{\circledR}\right)^{11}$ for grampositive bacteria, which was modified for mycobacteria. Briefly, colonies were taken from the solid culture medium, inactivated at $100^{\circ} \mathrm{C}$ in a thermoblock, and centrifuged at $13000 \mathrm{rpm}$ for 3 minutes. Then, the supernatant was removed. The cell button was suspended in $480 \mu \mathrm{L} 50 \mathrm{mM}$ EDTA. Lysis was performed with $50 \mu \mathrm{L}$ lysozyme (incubation at $37^{\circ} \mathrm{C}$ ) and $600 \mu \mathrm{L}$ lysis solution (incubation at $80^{\circ} \mathrm{C}$ ). Three microliters of RNAase (incubation at $37^{\circ} \mathrm{C}$ ) was added. Then, $250 \mu \mathrm{L}$ of the precipitation solution was added (vortex and incubation at $-20^{\circ} \mathrm{C}$ ). The supernatant was transferred to a tube with 600 $\mu \mathrm{L} 100 \%$ ethanol (washed with $600 \mu \mathrm{L} 70 \%$ ethanol). DNA button rehydration was performed with rehydration solution, and the samples were stored at $4^{\circ} \mathrm{C}$ for immediate use or at $-80^{\circ} \mathrm{C}$ for later use.

To identify mutations in the kat $G$, inh $A$, and $r p o B$ genes, the Genotype MTBDR plus V.2 test was used (Hain LifeScience, Germany, Table S1), following the instructions described in the insert of the commercial kit. ${ }^{12}$

\section{Definition of Terms}

The following terms are related to the clinical aspects and therapeutic outcomes.

- Clinical behavior: For the purposes of characterizing the patients, symptoms and semiologic findings were predominant in the patients. The symptoms were categorized into condensation syndrome, pleural effusion syndrome, and constitutional type (Table S2).

- Therapeutic outcome: This refers to the discharge condition defined by the TB control and eradication program. The outcomes were classified as cured, finished treatment, therapeutic failure, and death. Patients who were lost to follow-up were excluded, because the final discharge conditions could not be determined. ${ }^{1}$

\section{Statistical Analysis}

The data was entered into the Microsoft Excel 2010 program. For the univariate statistical analysis, Epi Info version 7.2.2.6 (Centers for Disease Control and Prevention, USA) was used. The bivariate analysis was performed with Stata software version 12.0. (StataCorp. 2011, College Station, TX). Nominal variables were presented using a frequency distribution. Confidence intervals were calculated for the estimates. Bivariate analysis was performed using Fisher's exact test for categorical variables. Statistical significance was considered at $P \leq 0.05$.

\section{Results}

\section{Sociodemographic Aspects}

A total of 101 patients diagnosed with TB were studied from December 2017 to December 2018; nine patients (8.91\%; 95\% confidence interval [CI] 4.16-16.24\%) were immigrants from Venezuela and had been settled in the city for an average of 3.4 months (95\% CI: 2.1-4.7 months). Three patients (33.33\%) came from the state of Zulia, 2 (22.22\%) came from the state of Miranda, and the remaining $4(11.11 \%)$ came from the states of Apure, Guárico, Sucre, and Táchira. Five patients were settled in locality 2, or Cienaga de la Virgen and Turística (55.56\%); 4 patients were settled in locality 3, or Industrial de la Bahía (44.44\%) in Cartagena de Indias.

The sample included a slightly higher proportion of women, representing 55.56\% (95\% CI: 21.2 - 86.3). The most common age group was 26 - to 35 -year-old patients, representing $44.4 \%$ (95\% CI: 13.7-78.8) (Figure S1).

A total of $66.67 \%$ (95\% CI: $29.93-92.51 \%)$ of immigrant patients stated that they were working in informal work, and 


\subsection{3\% (95\% CI: 7.49-70.07\%) were unemployed.}

\section{Risk Factors}

Among the associated factors, one patient (11.11\%) reported consuming illegal addictive substances. Coinfection with HIV in immigrants occurred in 4 patients (95\% CI: 44.44\%; 13.70 $78.80 \%)$. Two of the HIV coinfected patients had resistance to first-line anti-TB medications $(50 \% ; P=0.642)$. In relation to the native population, there was a higher frequency of cases of HIV coinfection in immigrants (6.52\% vs. $44.44 \% ; P=0.005)$. Other comorbidities, such as diabetes mellitus (9.78\%) and chronic obstructive pulmonary disease (COPD), appeared only in the native population (1.09\%). All immigrant patients (100\%; 95\% CI: 66.37-100\%) showed malnutrition, with an average BMI (body mass index, measured in kilograms $(\mathrm{kg})$ of weight in relation to height in meters (m)) of $15.49 \mathrm{~kg}$ / $\mathrm{m}^{2}\left(95 \%\right.$ CI $\left.13.92-17.06 \mathrm{~kg} / \mathrm{m}^{2}\right)$. In the native population, malnutrition occurred in $41.30 \%$ (95\% CI 31.13-52.05\%), and they had an average BMI of $19.68 \mathrm{~kg} / \mathrm{m}^{2}$ (95\% CI: 19.16-20.21 $\mathrm{kg} / \mathrm{m}^{2}$ ) (Table 1). No statistically significant relationship was found between being coinfected with HIV and malnutrition $(P=0.688)$.

\section{Sensitivity Profile}

Of the nine immigrants, 5 (55.56\%) had sensitive strains of $\mathrm{TB}$, and 4 had drug-resistant strains (44.44\%). Similar levels of sensitivity were found with the molecular biology and phenotypic tests (kappa 0.95; 95\% CI 0.75-0.97, $P<0.05$ ), except for a case of mono-resistance to isoniazid due to a mutation in the inhA gene that was found by the molecular test but not by the phenotypic test.

Three of the resistant TB patients came from the state of Zulia and settled in locality 2 in Cartagena de Indias. Two of these patients had multidrug-resistant (MDR) TB (22.22\%; 95\% CI 2.81-60.01\%) with katGS315T1 (AGC315ACC)/rpoBS531L (TGC/TTG) mutations; they also presented meningeal and pleural EPTB, and both patients died. The other patient from the state of Zulia presented resistance to rifampin (TBRR) (11.11\%; 95\% CI 0.28-48.25\%) with an rpoBS531L-type mutation (TGC/TTG); the patients presented meningeal-type EPTB and had therapeutic failure. There was also one patient from the state of Miranda who settled in locality 3; the patient presented mono-resistance to $\mathrm{H}$ (11.11\%; 95\% CI: 0.28 $48.25 \%$ ) with a mutation in the promoter region $-15 \mathrm{C} / \mathrm{T}$ of the inhA gene. The patient had therapeutic failure (Figure 1).

Figure 2 shows the mutations found in patients with resistant TB. Compared with the native population, immigrants had a higher frequency of resistant cases (15.22 vs. $44.44 \%$; $P=0.051)$.

\section{Clinical Aspects}

Pulmonary tuberculosis (PTB) was present in 5 patients (55.56\%; 95\% CI: 21.20-86.30\%), and extrapulmonary tuberculosis (EPTB) was present in 4 patients $(44.44 \%$; $95 \%$ CI 13.70-78.80\%). EPTB was more prevalent among immigrants than in the native population, which had prevalence rates of 4.49\% (95\% CI: $1.24-11.11 \% ; P=0.002)$ and $95.51 \%(95 \%$ CI: 88.89-98.76\%; $P=0.002$ ) for EPTB and PTB, respectively. Among the types of EPTB in immigrant patients, there were 2 cases of meningeal TB (22.22\%), one case of osteoarticular

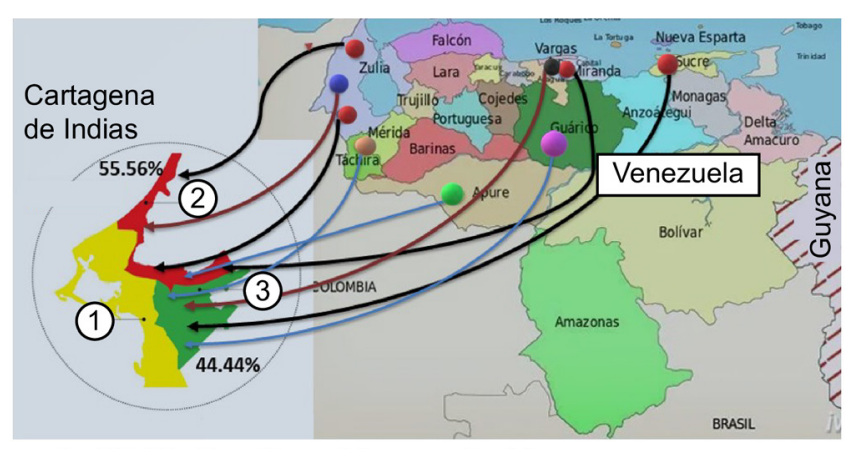

- RR-TB: Condition of therapeutic failure

- MDR-TB: Death condition

- Mutation inhA -15C/T: Condition of therapeutic failure

$\rightarrow$ Surviving patients with drug-sensitive TB who came from different states of Venezuela

(1)(2) Localities

Figure 1. Area of Origin of Immigrant Participants with TB.

Three cases with extra-pulmonary-type resistant TB came from the state of Zulia and settled in locality 2, of which two had MDR TB and died. Two patients came from the Miranda state, one of them, with sensitive TBP and HIV co-infection died; another case with inh A -15C/T type mutation ended in therapeutic failure. Both had settled in locality 3.

Table 1. Risk Factors

\begin{tabular}{|c|c|c|c|c|}
\hline \multirow{2}{*}{ Risk Factor } & \multicolumn{2}{|c|}{ Non-migrant } & \multicolumn{2}{|c|}{ Immigrant } \\
\hline & $\%(n)$ & $95 \%$ IC & $\%(n)$ & $95 \%$ IC \\
\hline Male & $73.91 \%(68)$ & $0.6371-0.8252$ & $44.44 \%(4)$ & $0.137-0.788$ \\
\hline Malnutrition & $41.30 \%(38)$ & $0.3113-0.5205$ & $100 \%(9)$ & $0.6637-0.100$ \\
\hline Co-infection with HIV & $6.52 \%(6)$ & $0.0243-0.1366$ & $44.44 \%(4)$ & $0.137-0.788$ \\
\hline Diabetes & $9.78 \%(9)$ & $0.0457-0.1776$ & $0 \%(0)$ & \\
\hline Alcoholism & $8.7 \%(8)$ & $0.0383-0.1642$ & $0 \%(0)$ & \\
\hline Illegal drug use & $18.48 \%(17)$ & $0.1115-0.2793$ & $11.11 \%(1)$ & $0.0028-0.4825$ \\
\hline Alcoholism & $7.61 \%(7)$ & $0.0311-0.1505$ & $0 \%(0)$ & \\
\hline $\mathrm{BMI}\left(\mathrm{kg} / \mathrm{m}^{2}\right)$ (mean value) & 19.68 & $19.16-20.21$ & 15.49 & $13.92-17.06$ \\
\hline
\end{tabular}

Abbreviations: BMI, body mass index; COPD, Chronic obstructive pulmonary disease; HIV, human immunodeficiency virus.

The immigrant population presented higher conditions of malnutrition and HIV co-infection, factors related to the development of active TB, and resistance to antituberculosis drugs. 


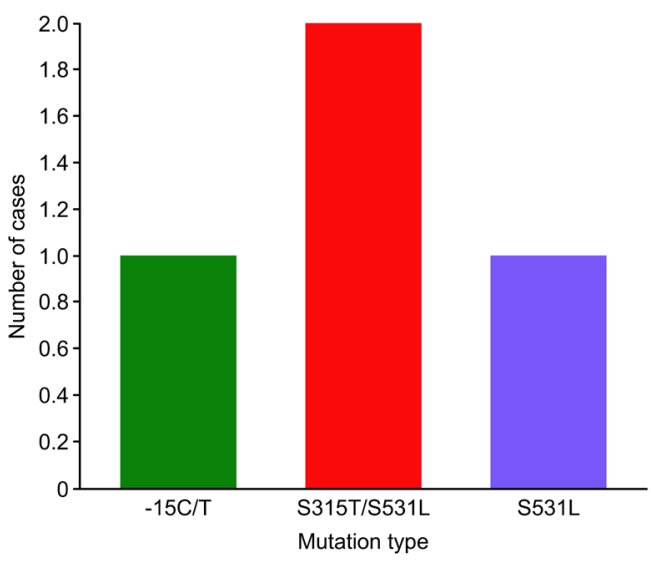

Figure 2. Spectrum of Mutations Found in Patients With Resistant TB. The patients with resistant TB had mutations in target regions in genes of the main anti-tuberculosis drugs, which include the promoter region of the inh $A$ gene, region 315 of the $k a t G$ gene, and the rifampicin resistance determining region in the $r p o B$ gene.

TB (11.11\%), and one case of pleural TB (11.11\%) (Figure S2).

The most frequent clinical presentation in immigrant patients was that of constitutional syndrome, which occurred in 7 patients (77.78\%; 95\% CI: 39.99-96.72\%). One patient had condensation syndrome, and another had pleural effusion syndrome (11.11\%; 95\% CI: 3.38-48.25\%).

Regarding the sensitivity profile in the immigrant patients with sensitive strains, 4 patients $(80 \%)$ had manifestations of constitutional syndrome, and one (20\%) had condensation syndrome. Three $(75 \%)$ of the patients with resistant strains had manifestations of constitutional syndrome, and one (25\%) had pleural effusion syndrome; this difference was statistically significant $(P=0.036$; Figure 3$)$.

Two patients were children aged under fifteen years old (22.22\%; 95\% CI: 2.81-60.01\%); one patient was a one-yearold with osteoarticular EPTB, and the other patient was a 2-year-old with BPD. The clinical manifestations in these patients were nonspecific, and the diagnostic impression was based on close contact with adults with active TB. The

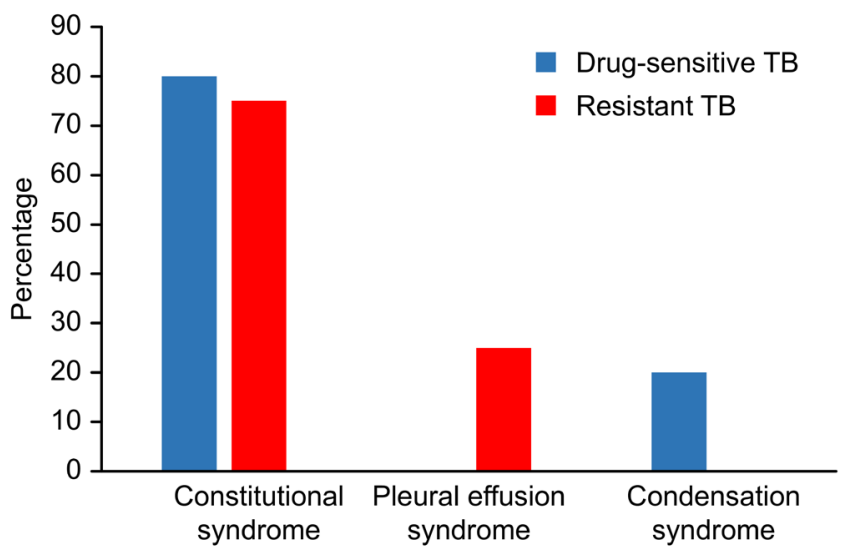

Figure 3. Physical Examination Findings and Sensitivity Profile in Immigrant Patients.

Immigrant patients with sensitive and resistant strains showed similar semiologic findings of constitutional type; however, those with resistance profile had more frequent cases of EPTB $(P=0.0357)$. radiological characteristics in the patient with $\mathrm{PTB}$ showed an interstitial pattern. Microbiological isolation was performed by sampling of induced sputum and in the patient with bone EPTB by culturing the inflammatory bone exudate. Sensitivity tests in these patients did not reveal resistance patterns. These patients were managed with the scheme of sensitive PTB and EPTB with an outcome in cure. Compared with the native population, immigrants had a higher prevalence of cases with constitutional manifestations $(26.09 \%$ vs. $77.78 \%$; $P=0.003)$ (Table 2).

In imaging studies, caverns were the most frequent finding on chest radiography in the immigrant population $(33.33 \%$; 95\% CI: 7.49-70.07\%). One patient with osteoarticular EPTB presented a fusion image and lytic lesions in the cervical spine at the C3 and C4 levels (11.11\%; 95\% CI: 0.28-48.25\%). Compared with native patients, immigrant patients had a higher prevalence of extrapulmonary images, such as pleural effusion $(6.52 \%$ vs. $11.11 \% ; P=0.045)$ and bone destruction (0.00\% vs. $11.11 ; P=0.045)$ (Table S3).

\section{Treatment and therapeutic outcome}

Patients initially received the standard regimen of rifampicin, isoniazid, pyrazinamide, and ethambutol (RHPE).

Patients who were diagnosed with resistance to anti-TB drugs underwent a change in their therapeutic regimen. One patient with mono-resistance to isoniazid due to the inhA$15 \mathrm{C} / \mathrm{T}$ mutation was managed as sensitive $\mathrm{TB}$ due to not showing resistance in the phenotypic test.

The patient with meningeal EPTB with rifampicinresistant strain type rpoBS531L was treated with levofloxacin, kanamycin, pyrazinamide, ethionamide, and ethambutol. The other patient with meningeal EPTB and the patient with pleural TB with MDR strains (katGS315T- rpoBS531L) received treatment with pyrazinamide, ethambutol, ethionamide, levofloxacin, kanamycin, and cycloserine.

Regarding discharge conditions, 2 patients were cured (22.22\%; 95\% CI: $2.81-60 \%), 3$ ended in therapeutic failure (33.33\%; 95\% CI: 7.49-70.07\%), and 4 died (44.44\%; 95\% CI $13.70-78.80 \%)$. Compared with the native population, the immigrant patients with TB had a higher prevalence of undesired outcomes, such as therapeutic failure $(8.70 \%$ vs. $33.33 \% ; P=0.001)$ and death $(4.35 \%$ vs. $44.44 \% ; P=0.001)$ (Table 3).

Two of the patients who died had sensitive PTB (50\%), and 2 had katGS315T-rpoBS531L type MDR-TB (50\%) with extrapulmonary manifestations. One of the deceased patients with sensitive PTB came from the state of Miranda, and the other came from Sucre; both patients were coinfected with HIV, presented symptoms of constitutional syndrome, and had a cavernous pattern image. The patients with MDR TB who died came from the state of Zulia; they had settled in locality 2 in Cartagena de Indias and presented pleural and meningeal EPTB.

\section{Discussion}

Migratory waves have contributed to an increased number of TB cases, especially in countries that have medium and low incidence rates. TB patients from other countries import 
Table 2. Physical Examination Findings in All Participants

\begin{tabular}{lccc}
\hline & Constitutional Syndrome & Condensation Syndrome & Pleural Effusion Syndrome \\
\hline Immigrants, $\mathrm{n}(\%)$ & $7(77.78)$ & $1(11.11)$ & $1(11.11)$ \\
Native population, $\mathrm{n}(\%)$ & $24(26.09)$ & $62(67.39)$ & $6(6.52)$ \\
Total, $\mathrm{n}(\%)$ & $31(30.69)$ & $63(62.38)$ & $7(6.91)$ \\
\hline
\end{tabular}

Immigrant cases had a higher frequency of presentation of constitutional syndrome than the native population $(P=0.003)$.

Table 3. Discharge Conditions in All Participants

\begin{tabular}{|c|c|c|c|c|c|}
\hline & Death & Cured & Finished Treatment & Therapeutic Failure & Total, n (\%) \\
\hline Immigrants n (\%) & $2(22.22)$ & $0(0.00)$ & $3(33.33)$ & $4(44.44)$ & $9(8.91)$ \\
\hline Native patients n (\%) & $64(69.57)$ & $16(17.39)$ & $8(8.70)$ & $4(.35)$ & $92(91.09)$ \\
\hline Total, n (\%) & $66(65.35)$ & $16(15.84)$ & $11(10.89)$ & $8(7.92)$ & $101(100)$ \\
\hline
\end{tabular}

Therapeutic failure and death were more frequent in immigrant patients in the study $(P=0.001)$.

potentially mutant strains, and these patients may not have completed the treatment started in their country of origin. In this study, 8.91\% (95\% CI: 4.16-16.24\%) were immigrants from Venezuela. By the time this study was conducted, 346 cases of TB had been reported in Cartagena de Indias (according to DADIS Cartagena records), of which 25 (7.22\%) were found in Venezuelan immigrants. In Colombia, according to the 2017 INS report, $0.2 \%$ of all TB cases in Colombia corresponded to the immigrant population in $2016 .{ }^{13}$

Many immigrants have to work in unclassified activities. ${ }^{14}$ A total of $66.67 \%$ (95\% CI: $29.93-92.51 \%$ ) of the immigrant participants in this study stated that they were working in informal jobs. The most common activities were those that involved contact with the public, such as minority commerce and street vending; these situations favor the spread of TB.

The difficult economic situation that some immigrants face in both their country of origin and their host country precludes access to a balanced diet; that fact is reflected in their musculoskeletal state. All immigrant patients studied herein were in a state of malnutrition (100\%; 95\% CI: 66.37-100\%; X BMI: 15.49 (95\% CI: 13.92-17.06)). Malnutrition (MNT) was not related with any other factor, including coinfection with HIV $(P=0.688)$. The relationship between MNT and TB is interactive because prolonged MNT makes people more susceptible to infectious-contagious pathologies, and, in turn, TB leads to or worsens MNT. ${ }^{15}$ Nutritional deficits can lead to impaired immune homeostasis, which greatly increases an individual's susceptibility to infection progression. ${ }^{16,17}$

$\mathrm{TB}$ in the immigrant population has some common characteristics that are globally recognized. These include a younger average age, which is explained by the search for job offers. ${ }^{18-21}$ Casals et al ${ }^{22}$ carried out a literature review on TB and immigration in Spain between 1998 and 2012. They found 219 publications that included differential characteristics between immigrants and native populations. The average age was lower in immigrants; $93.5 \%$ were aged under 51, while in the local population, $64.9 \%$ were aged under 51 . Furthermore, they found that the prevalence of resistance to isoniazid was $3.8 \%$ in natives and $7 \%$ in immigrants. ${ }^{22}$

Another feature of $\mathrm{TB}$ in immigrants is an increased presentation of EPTB. The frequency of EPTB in the group of immigrant patients was higher than that of the autochthonous population ( $44.44 \%$ vs. $4.35 \% ; P=0.002)$. The 2 cases of meningeal TB were related to the nonapplication of the Calmette Guerin (BCG) vaccine, which is applied at the neonatal stage to protect against serious forms of $\mathrm{TB}$, such as meningeal and miliary $\mathrm{TB}^{23}$

The tendency for extrapulmonary dissemination in the strains that infect migrant patients confers characteristics of clinical behavior. The presence of cavitation with hypervirulent strains that produce cord factor or trehalose dimycolate has been described. ${ }^{24}$ Some authors have described the increased presence of lung cavitation in immigrants. ${ }^{18}$ In the immigrant patients in this study, cavitation was the most frequent finding on radiography thorax (33.33\%; 95\% CI: 7.49-70.07\%) and of extrapulmonary images such as pleural effusion $(11.11 \%$ vs. $6.52 \% ; P=0.065)$ and bone destruction.

Pierluigi et $\mathrm{al}^{25}$ carried out a comparative study in 236 patients (44\% were natives; $56 \%$ were immigrants) in northern Italy. They found that immigrants were younger than natives on average ( 30.5 vs. $62.2 \%$; $P=0.001$ ), had more radiological signs of cavitary lesions ( 54.5 vs. $33.8 \% ; P=0.004$ ), and had a higher prevalence of coexisting chronic noncommunicable diseases (17.4\% vs. $8.0 \%)$. The prevalence of resistance to any medication was $25.7 \%$ among immigrants, and the prevalence of MDR was $3.9 \%$. In addition, they found no significant difference in resistance between native and immigrant patients $(29.2 \%$ vs. $19.6 \%$; $P=0.138) .{ }^{25}$

In the current study, a higher proportion of resistant cases was found among immigrants than among native immigrants ( $44.44 \%$ vs. $15.22 \% ; P=0.050$ ). The tendency to spread and resist foreign strains raises an alert for the possible presence of hypervirulent strains. ${ }^{26}$ One patient in this study who was from the state of Miranda had a mutation in the promoter region $-15 \mathrm{C} / \mathrm{T}$ of the inh $A$ gene; however, no resistance was detected in the phenotypic test, although the patient had therapeutic failure. Another patient from the same state who had sensitive PTB and was coinfected with HIV died. Both patients had settled in the same locality in Cartagena de Indias. In this study, strains were found with katGS315T/ rpoBS531L mutations, which confer MDR resistance; these strains were present in patients from the state of Zulia who had settled in locality 2 , which is an economically depressed area in Cartagena de Indias. These strains exhibited hypervirulent 
behavior, manifesting with a clinical picture of constitutional type, extrapulmonary spread, and a fatal outcome. In a sensitivity identification study on $59 \mathrm{M}$. tuberculosis strains in Venezuela (Sucre state), Mendoza et $\mathrm{al}^{27}$ found prevalence rates of $6.3 \%$ and $14.3 \%$ for primary resistance and acquired resistance, respectively. They found one MDR strain and one strain with RR. They identified 2 other mutation points in the $r p o B$ gene, different than the one found in our group of patients. The positions with changes were 516,526 , and $531 .^{27}$ Among our immigrant participants, one came from the state of Sucre (Venezuela). This patient had a grade II malnutrition status and was found to be very smear-positive (positive +++ ). Sensitivity tests did not show drug resistance, but the patient died during treatment with the RHPE scheme.

In another study carried out with data from the National Reference Laboratory for Tuberculosis on 193 patients from different areas of Venezuela, researchers detected the presence of mutations in the katG gene in 19 isolates (9.8\%), of which 17 had resistance to other anti-TB drugs (6.2\%), including 11 patients with resistance to rifampicin (64.7\%). Six of the multiresistant clinical isolates presented resistance to 4 antimicrobials. ${ }^{28}$

The clinical and microbiological characteristics of the immigrant patients were different than those of the local population with respect to undesired outcomes, such as therapeutic failure $(8.70 \%$ vs. $33.33 \% ; P=0.001)$ and death (4.35\% vs. $44.44 \% ; P=0.001)$.

This study was descriptive, and therefore, an association between the type of sensitivity of the strains and the clinical characteristics in the study participants was not examined; however, statistically significant data was found between immigrants and constitutional-type clinical behavior, resistance to anti-TB, and undesired outcomes.

$\mathrm{TB}$, along with measles, diphtheria, Chagas disease, HIV, and malaria, are among the infectious pathologies that have resurfaced in the countries bordering Venezuela as a result of the migration of its inhabitants. Colombia is among the countries that have been most affected by these pathologies within the problem of migratory waves. ${ }^{29}$

\section{Conclusion}

Immigrants have contributed to the increase in incidence of $\mathrm{TB}$ in the city of Cartagena de Indias, representing $8.91 \%$ of the patients studied herein. They came from geographical areas where the presence of virulent strains has been demonstrated, and they had conditions such as coinfection with HIV and malnutrition; thus, these patients presented particular clinical characteristics such as constitutional manifestations, extrapulmonary spread, the presence of caverns, and undesired outcomes such as therapeutic failure and death. Disease control programs should take these characteristics into account in the immigrant population to prevent the spread of potentially hypervirulent strains.

\section{Authors' Contributions}

DFR: Conducted the clinical study of the patients, performed the microbiological tests, analyzed the data and wrote the manuscript. EM: Analyzed the statistical data. LCM:

\section{Research Highlights}

\section{What Is Already Known?}

The socio-economic situation of immigrants has contributed to the increase in $\mathrm{TB}$ cases and mortality from this disease.

\section{What This Study Adds?}

Immigrant $\mathrm{TB}$ patients in Cartagena de Indias were more likely to present particular clinical characteristics, such as HIV coinfection, malnutrition, constitutional manifestations, extrapulmonary spread, and undesired outcomes such as therapeutic failure and death.

Participated in epidemiological management and surveillance of participants. CLP: Performed the sensitivity tests. DGC: Leader of the research group and analyzed the experiments and the manuscript.

\section{Conflict of Interest Disclosures}

The authors declare that they have no conflicts of interest.

\section{Ethical Approval}

The research work had the approval of the ethics committee of the University of Cartagena (Act 80 of July 3, 2015). Participants were asked for informed consent to participate in the study.

\section{Funding/Support}

This project was financed by DADIS Cartagena and Colciencias, in agreement with Colfuturo (Call No. 727 of 2015), Doctorate Strengthening and Group Strengthening, University of Cartagena, 2018.

\section{Acknowledgements}

The authors thank the UNIMOL Research Group of the University of Cartagena and the National Network of Mycobacteria Laboratory, Colombia; Dr. Rocío Gómez Ortega from CINVESTAV (Mexico City) for her guidance; the DADIS District Health Department; and Doctors Rubén Gómez Arias and Gustavo Mora García for their collaboration in the development of this project.

\section{Supplementary Materials}

Supplementary file 1 contains Tables S1-S3 and Figures S1-S2.

\section{References}

1. World Health Organization (WHO). Global Tuberculosis Report 2019. Geneva, Switzerland: WHO; 2019.

2. Jilani TN, Avula A, Zafar Gondal A, Siddiqui AH. Active Tuberculosis. Treasure Island, FL: StatPearls Publishing; 2019.

3. Organización Internacional para las Migraciones (OIM). Conceptos generales sobre las migraciones. http://www.oim.org. co/node/13. Accessed December 12, 2019

4. Pescarini JM, Rodrigues LC, Gomes MG, Waldman EA. Migration to middle-income countries and tuberculosis-global policies for global economies. Global Health. 2017;13(1):15. doi:10.1186/ s12992-017-0236-6.

5. Internacional Organization for Migration (IOM). World Migration 
Report 2018. Mandaluyong, Philippines: Barangay Ginebra San Miguel; 2018. Geneva, Switzerland: IOM; 2018.

6. Organización Mundial de la Salud (OMS). Promoción de la salud de los refugiados y los migrantes: proyecto de marco de prioridades y principios rectores para promover la salud de los refugiados y los migrantes: informe de la Secretaría. Geneva, Switzerland: OMS; 2017.

7. Ministerio de Salud de Colombia. Plan de Respuesta del Sector Salud al Fenómeno Migratorio. Bogotá, Colombia: Ministerio de Salud de Colombia; 2017.

8. Departamento Administrativo Nacional de Estadísticas. Resultados censo nacional de población y vivienda 2018. Bogotá, Colombia: DANE; 2019.

9. Organización Panamericana de la Salud. Manuel para el diagnóstico bacteriológico de la tuberculosis: Normas y guía técnica. Parte II Cultivo. Washington, DC: Organización Panamericana de la Salud; 2008.

10. Becton Dickinson Company. Sistema BBL MGIT AST SIRE para la prueba de sensibilidad antimicobacteriana de Mycobacterium tuberculosis. Franklin Lakes, NJ: Becton Dickinson Company; 2016.

11. Promega. Wizard ${ }^{\circledR}$ Genomic DNA Purification Kit. Technical manual. Madison, WI: Promega; 2015.

12. Hain Lifescience. GenoType MTBDRplus ver 2.0: Instructions for Use. Nehren, Germany: Hain Lifescience; 2015.

13. Instituto Nacional de Salud. Tuberculosis en Colombia. 2017. Bogotá, Colombia: Instituto Nacional de Salud; 2017.

14. Fedesarrollo. Informe mensual del mercado laboral. Migración venezolana a Colombia. Santa Fe, Bogotá: Fedesarrollo; 2018.

15. Ikeogu MO, Wolf B, Mathe S. Pulmonary manifestations in HIV seropositivity and malnutrition in Zimbabwe. Arch Dis Child. 1997;76(2):124-128. doi:10.1136/adc.76.2.124.

16. Cegielski JP, McMurray DN. The relationship between malnutrition and tuberculosis: evidence from studies in humans and experimental animals. Int J Tuberc Lung Dis. 2004;8(3):286-298.

17. Chandrasekaran P, Saravanan N, Bethunaickan R, Tripathy S. Malnutrition: modulator of immune responses in tuberculosis. Front Immunol. 2017;8:1316. doi:10.3389/fimmu.2017.01316.

18. Ramos JM, Masiá M, Rodríguez JC, Padilla I, Soler MJ, Gutiérrez F. [Tuberculosis in immigrants: clinical and epidemiological differences as compared to the native population (1999-
2002)]. Enferm Infecc Microbiol Clin. 2004;22(6):315-318. doi:10.1157/13063041.

19. Odone A, Tillmann T, Sandgren A, et al. Tuberculosis among migrant populations in the European Union and the European Economic Area. Eur J Public Health. 2015;25(3):506-512. doi:10.1093/eurpub/cku208.

20. European Centre for Disease Prevention and Control (ECDC). Tuberculosis surveillance and monitoring in Europe, 2019. Solna Municipality, Sweden: ECDC; 2019.

21. Ballesteros AL, Oriol J, Francisco I, Fernández S, García Bragado F, Vinyes A. Clinical characteristics of tuberculosis in immigrants and autochthonous populations in two hospitals of Catalonia. Rev Clin Esp. 2014;214(8):445-452. doi:10.1016/j.rceng.2014.07.001.

22. Casals M, Rodrigo T, Camprubí E, Orcau A, Caylà JA. [Tuberculosis and immigration in Spain: scoping review]. Rev Esp Salud Publica. 2014;88(6):803-809.doi:10.4321/s1135-57272014000600011.

23. Luca S, Mihaescu T. History of BCG vaccine. Maedica (Buchar). 2013;8(1):53-58.

24. Lang R. Recognition of the mycobacterial cord factor by Mincle: relevance for granuloma formation and resistance to tuberculosis. Front Immunol. 2013;4:5. doi:10.3389/fimmu.2013.00005.

25. Pierluigi B, Erika M, Francesca $C$, et al. Tuberculosis in Native Residents and Immigrants in an Area of Northern Italy: A Ten Years Survey. Paper presented at: 22nd European Congress of Clinical Microbiology and Infectious Diseases; 2012; London, UK.

26. Salas-Coronas J, Rogado-González MC, Lozano-Serrano $A B$, Cabezas-Fernández MT. Tuberculosis and immigration. Enferm Infecc Microbiol Clin. 2016;34(4):261-269. doi:10.1016/j. eimc.2015.12.010.

27. Mendoza R, De Donato M, de Waard JH, Takiff H, Bello T, Chirinos G. [Susceptibility of M. tuberculosis to antituberculosis drugs as determined by two methods, in Sucre state, Venezuela]. Invest Clin. 2010;51(4):445-455.

28. Romay Z, Arráiz N, Fuenmayor A, Ramírez C, Rojas L, París R. [Detection of S315T mutation in the katg gene as a strategy for identification of isoniazid-resistant Mycobacterium tuberculosis in a reference laboratory]. Rev Chilena Infectol. 2012;29(6):607-613. doi:10.4067/s0716-10182012000700004.

29. Tuite AR, Thomas-Bachli A, Acosta H, et al. Infectious disease implications of large-scale migration of Venezuelan nationals. J Travel Med. 2018;25(1). doi:10.1093/jtm/tay077. 